\title{
PEDAGOSELFIE: \\ OS SIGNIFICADOS DO CORPO E DA IMAGEM NA PRODUÇÃO DE AUTORRETRATOS ENTRE JOVENS MENINAS
}

\begin{abstract}
PEDAGOSELFIE:
THE SIGNIFICATIONS OF BODY AND IMAGE IN THE PRODUCTION OF SELFPORTRAITS AMONG YOUNG GIRLS

PEDAGOSELFIE

LOS SIGNIFICADOS DEL CUERPO Y DE LA IMAGEN EN LA PRODUCCIÓN DE AUTORRETRATOS ENTRE ALUMNAS LICEALES

Luiz Felipe Zago¹; Bianca Salazar Guizzo²; Evelyn Santos Pereira ${ }^{3}$

\section{RESUMO}

O artigo realiza uma investigação teórica sobre as condições culturais da visibilidade dos corpos por meio da prática de produção e publicação de autorretratos - as chamadas selfies - feitos por jovens meninas. 0 objetivo é analisar, a partir de uma perspectiva culturalista, os modos como meninas estudantes do 10 ano do Ensino Médio de uma escola pública do Rio Grande do Sul utilizam-se de telefones celulares e redes sociais para produzir e compartilhar suas selfies. A metodologia consistiu na realização de três grupos de discussão com as estudantes da escola selecionada que se voluntariassem a falar sobre corpo, imagem e tecnologia, sob a coordenação de uma pesquisadora. Cria-se o neologismo pedagoselfie para designar, com base nas análises das falas das participantes, a operação de determinada pedagogia no processo de ensinagem-aprendizagem de significados e práticas de produção de selfies - significados para os quais convergem pedagogia, corpo, imagem e tecnologia. Conclui-se que a produção e publicação de selfies podem estar articuladas à circunscrição de um regime de visibilidade singular do tempo presente, na medida em que a exposição da imagem de si ao outro depende de um escrutínio visual que regula a produção, edição e publicação de selfies em redes sociais on-line.
\end{abstract}

PALAVRAS-CHAVE: Corpo. Imagem. Redes Sociais. Pedagogia Cultural.

\section{ABSTRACT}

The article undertakes a theoretical inquiry of the cultural conditions of body visibility through the practice of production and publication of self-portraits - called selfies - made by young girls. The objective is to analyze, from a culturalist approach, the ways how female students of one level of Public Brazilian High School use smartphones and social media to produce and share their selfies. The methodology design consisted of three meetings for discussion on the topics of body, image and technology, which were performed by one researcher with the volunteers. The neologism pedagoselfie is created to address the operation of a kind of pedagogy in the process of teaching and learning the significations and practices implied by the production of selfies, significations that encompass pedagogy, body, image and technology. It concludes that both the production and publication of selfies may be articulated to the circumscription of a singular regime of visibility

\footnotetext{
${ }^{1}$ Doutorado em Educação - Universidade Federal do Rio Grande do Sul (UFRGS) - Porto Alegre, RS - Brasil. Professor Permanente - Universidade Luterana do Brasil (ULBRA) - São José, Canoas, RS - Brasil. E-mail: luizfelipezago@ulbra.edu.br ${ }^{2}$ Doutorado em Educação - Universidade Federal do Rio Grande do Sul (UFRGS) - Porto Alegre, RS - Brasil. Professora e Pesquisadora - Universidade Luterana do Brasil (ULBRA) - São José, Canoas, RS - Brasil. E-mail: bguizzo1@ @otmail.com

${ }^{3}$ Doutoranda em Educação - Universidade Luterana do Brasil (ULBRA) - São José, Canoas, RS - Brasil. Professora da Educação Básica - Prefeitura Municipal de Canoas. E-mail: evelynsantospereira@yahoo.com.br
}

Submetido em: 07/09/2017 - Aceito em: 09/01/2018
(C) ETD- Educação Temática Digital
Campinas, SP
v.20 n.4
p.1096-1116
out./dez. 2018 
of the present time, according as the exposition of a image of oneself to the other depends of a visual scrutiny the regulates the production, edition and publication of selfies on online social media.

KEYWORDS: Body. Image. Social Media. Cultural Pedagogy.

\section{RESUMEN}

En este artículo se presenta una investigación teórica sobre las condiciones culturales de la visibilidad de los cuerpos por medio de la práctica de producción y publicación de autorretratos - los así llamados selfies- que realizan niñas en jovenes. El objetivo es analizar, desde una perspectiva culturalista, los modos en los que las alumnas de 1으 año de Enseñanza Secundaria de un liceo público de Rio Grande do Sul (Brasil) se sirven de los teléfonos celulares y de las redes sociales para producir y compartir sus selfies. La metodología consistió en la realización de tres grupos de discusión con las estudiantes de dicho liceo que, voluntariamente, aceptaran hablar sobre cuerpo, imagen y tecnología, bajo la coordinación de una investigadora. Se creó el neologismo pedagoselfie para designar, tomando como base las intervenciones de las participantes, la operación de determinada pedagogía en el proceso de enseñanza-aprendizaje de significados y prácticas de producción de selfies, significados hacia los cuales convergen pedagogía, cuerpo, imagen y tecnología. Se concluye que la producción de selfies puede estar articulada a la circunscripción de un régimen de visibilidad singular de los tiempos que corren, en la medida en que la exposición de la imagen de sí dirigida al otro depende de un escrutinio visual que regula la producción, edición y publicación de selfies en redes sociales en línea.

PALABRAS CLAVE: Cuerpo. Imagen. Redes sociales. Pedagogía Cultural.

\section{INTRODUÇÃO}

O uso disseminado de aparelhos eletrônicos, em especial celulares, tablets, câmeras fotográficas e computadores, vem transformando hábitos e comportamentos em diferentes culturas. Com a popularização desse aparato tecnológico, do qual fazemos uso no dia a dia, desenvolvem-se diferentes formas de estar no mundo, diferentes sensibilidades, diferentes modos de interação entre os indivíduos e, também, diferentes maneiras de constituir-se sujeito. Graças a certos dispositivos tecnológicos, como esses recém-mencionados, os regimes de visibilidade a eles correlatos organizam hoje diferentes relações de poder: "ampliam-se e modificam-se as margens do visível, os modos de fazer ver, assim como os modos de ser visto" (BRUNO; KANASHIRO; FIRMINO, 2010, p. 7).

Se vivemos um período histórico e cultural em que, como argumenta Paula Sibilia (2004, p. 68), “a visibilidade e o reconhecimento no olhar alheio são fundamentais na definição do que cada um é", aprender a tornar o corpo uma bela imagem é uma prática tão importante quanto saber cuidar da saúde. Isso porque pouco valem os investimentos na produção de um corpo em consonância com os padrões estéticos e com os estilos de vida ditos saudáveis se o indivíduo não sabe materializar e divulgar sua adequação à moral da carne (SIBILIA, 2004; SOARES, 2009) por meio de imagens que possam ser vistas e admiradas. As imagens que divulgamos - ou que são divulgadas - de nós mesmos(as) mostram quem somos (ou quem queremos ser) ao(s) outro(s): esse é um aspecto do "totalitarismo fotogênico" hoje vigente (SANT'ANNA, 2005), sobretudo, nas redes sociais on-line. A partir da produção do corpo em imagem, podemos mostrar o melhor ou o pior de nós em muitas versões, que podem ser melhoradas, filtradas, editadas e "purificadas" de

$$
\text { (C) ETD-Educação Temática Digital Campinas, SP } \quad \text { v.20 } \quad \text { n.4 } \quad \text { p.1096-1116 out./dez. } 2018
$$


toda imperfeição que o corpo pode apresentar na sua forma orgânica, não mediada por tecnologias. O corpo pode ser o legitimador de nosso status social e pode, igualmente, ser o detrator de nossa estultícia (COSTA, 1998).

Sublinha-se que a expansão dos serviços de internet em dispositivos digitais, como os smartphones com câmeras fotográficas acopladas, contribui para a emergência de formas novas de interação e de práticas culturais, dentre as quais, despontam a produção de álbuns imagéticos pessoais publicados em redes sociais (ZAGO; SANTOS, 2014), em que o corpo é, muitas vezes, protagonista. Parece que o mundo está se tornando uma grande vitrine de vidas e corpos feitos de imagens (SÁ; POLIVANOV, 2012). Por meio da internet, em especial nas redes sociais on-line, não só é possível acessar a "vida imagética" de outras pessoas, como ainda se torna possível produzir, editar e divulgar nossas próprias "vidas imagéticas" em uma sucessão de álbuns fotográficos autobiográficos. É a partir dessa condição cultural da visibilidade dos corpos que algumas práticas encontram possibilidade de emergência e se tornam recorrentes. Especificamente para este artigo, detemo-nos na produção de imagens de si chamadas selfies.

O termo selfie ganhou popularidade nos Estados Unidos para designar a prática de fazer autorretrato utilizando a câmera do celular, a webcam ou outra câmera fotográfica, com o objetivo de publicá-lo em redes sociais. Nos autorretratos, o(a) protagonista pode estar sozinho(a), com amigos(as), namorado(a) ou celebridades, pode destacar o corpo inteiro ou partes dele, pode mostrar-se em algum lugar ao qual queira dar destaque, como em festas, eventos ou viagens. Com a popularização das selfies em escala mundial, as fotos de si mesmo(a) ganharam diferentes formatos e estilos, por exemplo: selfies de academia, de festa, de monumentos importantes, de viagens, selfies acordando, comendo, pós-sexo, engraçadas, entre tantas outras modalidades que acabam seguindo um mesmo padrão: o(a) autor(a) da imagem é também o(a) ator/atriz da imagem.

O processo de tornar o corpo uma imagem visível (e desejável) envolve domínio técnico de equipamentos usados para a produção dessa imagem. Para tanto, há habilidades concretas de manejo de certos dispositivos que precisam ser aprendidas e ensinadas. Aqui preferimos não apenas sublinhar os aspectos técnicos necessários para a produção de imagens dos corpos, mas, sobretudo, articular uma determinada forma de subjetivação do tempo presente aos modos como as tecnologias são utilizadas para esse fim. Nas experimentações para produzir imagens dos corpos, os indivíduos veem seus defeitos, aprendem a escondê-los, testam seus melhores ângulos, criam expressões faciais que mais Ihes favorecem e fazem poses que podem destacar, sempre com o auxílio da tecnologia, o que suas carnes têm de melhor. Nesse sentido, o processo que chamamos de pedagoselfies é aquele em que atua um conjunto de práticas culturais, valores morais e normas sociais que circunscrevem e constituem os modos possíveis de produção de imagens de si por si

$$
\text { (C) ETD-Educação Temática Digital Campinas, SP } \quad \text { v.20 } \quad \text { n.4 } \quad \text { p.1096-1116 out./dez. } 2018
$$


mesmo(a) por meio da utilização de dispositivos tecnológicos. O neologismo pedagoselfie, por nós criado, justamente pretende referir-se ao conjunto de práticas de transformação do corpo nesse tipo de imagem - de si, tirada por si mesmo(a) - constituído por relações de aprendizagem experimentadas mediante intensas negociações entre cultura e tecnologia tendo o corpo como objeto principal.

Nosso objetivo neste artigo é analisar, a partir de uma perspectiva culturalista, os modos como jovens meninas do 10 ano do Ensino Médio de uma escola pública do Litoral Norte do Rio Grande do Sul utilizam-se de telefones celulares e redes sociais (como o aplicativo WhatsApp e o Facebook) para produzir e compartilhar imagens de si feitas por elas próprias. Interessa-nos focalizar as maneiras como certa forma de subjetivação vem se consolidando no tempo presente junto a esse grupo, tal que vincula o uso cotidiano de tecnologias digitais à produção e divulgação de imagens de corpos em que os indivíduos são seus autores(as) e seus atores/atrizes, simultaneamente - as selfies. Como a produção de imagens participa da significação dos corpos para essas meninas? Quais estratégias são empregadas na produção das selfies? Quais forças atuam na subjetivação das jovens meninas na articulação entre tecnologias digitais de imagem e experimentação dos seus corpos? O conjunto das análises que delineiam respostas a essas perguntas deu condições para a criação do termo pedagoselfie, anteriormente mencionado, que será mais bem caracterizado na seção "Uma pedagogia do corpo feito em imagem".

Destacamos que não são o foco das análises deste estudo as imagens/selfies produzidas pelas meninas - portanto, não operamos com análise visual. Exclusivamente a partir de trechos de falas recortados de encontros de discussão feitos com as jovens meninas, empenhamo-nos em analisar as condições que permitem a multiplicação visual de imagens de si produzidas por si mesmo(a) e as formas como essas condições forjam maneiras singulares de viver os corpos, as feminilidades e as juventudes. Assim, nossa argumentação segue estas etapas: fazemos uma breve consideração acerca da metodologia desenvolvida na pesquisa e suas implicações éticas; apresentamos e explicamos o neologismo pedagoselfie, com base em um conjunto de conceitos que sustentam a criação desse termo; trazemos alguns trechos de falas das jovens meninas participantes da pesquisa que estimulam a pensar sobre suas práticas de produção de selfies, ora condizentes com nosso arcabouço conceitual, ora dele divergindo; por último, propomos algumas considerações provisórias sobre as práticas de produção do corpo em imagem no tempo presente. Ressaltamos que este é apenas um recorte do material empírico produzido para esta pesquisa, cuja complexidade aponta para múltiplas direções passíveis de serem analisadas. Para este artigo, escolhemos estrategicamente elementos que as jovens meninas trouxeram durante a pesquisa para apontar, de forma parcial e contingente, alguns
(C) ETD- Educação Temática Digital
Campinas, SP
v.20 n.4
p.1096-1116
out./dez. 2018 
entrecruzamentos que têm o corpo como ponto articulador e que nos auxiliam a evidenciar a pertinência do termo pedagoselfie.

\section{MÉTODO E IMPLICAÇÕES ÉTICAS DE PESQUISA}

Realizamos os grupos de discussão com jovens meninas estudantes de uma escola estadual de Educação Básica localizada em uma região litorânea, no município de Cidreira, no Rio Grande do Sul. Cidreira é uma das praias mais próximas de Porto Alegre e recebe turistas da região metropolitana e do interior do estado. De acordo com dados do Instituto Brasileiro de Geografia e Estatística (2014), a população residente de Cidreira é de 12.668 habitantes; estima-se que no período de veraneio (meses de dezembro, janeiro e fevereiro) esse número triplique. A Escola foi fundada em 1927, sendo uma das mais antigas da região. Possuía, à época da realização da pesquisa, 1.100 alunos(as), entre turmas de Ensino Fundamental e Ensino Médio politécnico, técnico integrado ao Ensino Médio e técnico pósmédio, além da modalidade EJA (Educação de Jovens e Adultos). Funcionava nos três turnos. Contava, então, com uma equipe de 45 professores(as) e 18 funcionários(as).

A Escola atende um público muito variado de alunos(as): filhos(as) de comerciantes locais e regionais, de funcionários(as) da prefeitura, dos(as) próprios(as) professores(as), de diaristas, de trabalhadores da construção civil local, etc. Alguns(mas) alunos(as) trabalham no turno inverso ao da escola, principalmente durante o período de veraneio, e outros(as) só estudam. Esta heterogeneidade ocorre porque a Escola é a única que oferece Ensino Médio em Cidreira, não havendo, portanto, outras opções.

O desenho metodológico da pesquisa teve dois momentos. Houve um levantamento inicial junto aos(às) alunos(as) da Escola para sondar seu interesse em participar da pesquisa. Nessa sondagem, valemo-nos da aplicação de um questionário junto a uma das turmas de 10 ano de Ensino Médio para que pudéssemos ver se a temática relacionada à produção de selfies despertaria o interesse dos(as) alunos(as).

Feito o levantamento inicial sobre a aceitação da temática e a participação dos(as) alunos(as), houve o convite, o agendamento e a realização de três grupos de discussão com as jovens meninas estudantes da Escola que desejassem falar sobre corpo, imagem e tecnologia. Este foi o segundo momento da metodologia de produção de dados. Os grupos de discussão foram gravados em áudio e vídeo e depois transcritos. A pesquisa, submetida a um Comitê de Ética em Pesquisa (CEP) com Seres Humanos ${ }^{4}$, foi aprovada.

No primeiro encontro do grupo de discussão, foram propostas duas atividades para as meninas presentes, nove no total. Explicou-se a dinâmica de um grupo de discussão, mostrando que era preciso que houvesse um(a) moderador(a), que apresentaria questões,

\footnotetext{
${ }^{4}$ A aprovação está registrada sob o número CAAE 44114414.1.0000.5349.

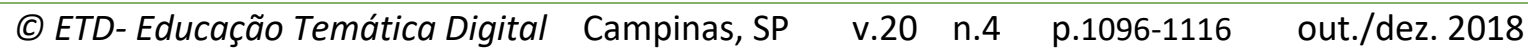


fosse na forma de perguntas ou em algum tipo de material que servisse como deflagrador para a discussão. No primeiro encontro e nos dois seguintes, a moderadora foi uma das pesquisadoras responsáveis. Na primeira atividade, uma das pesquisadoras expôs diversas imagens - selfies femininas, de mulheres fazendo poses variadas em ambientes variados ${ }^{5}$. Pediu-se que as meninas organizassem as imagens em grupos, cujos critérios para separação elas teriam que estipular. O objetivo desta atividade era verificar como elas próprias categorizariam e nomeariam tais fotografias e quais significados seriam atribuídos a cada tipo de selfie. Na segunda atividade, as meninas foram convidadas a escolher algumas fotografias das que foram distribuídas durante a primeira atividade e a colar as escolhidas em uma folha. A tarefa era fazer uma legenda para cada uma das selfies escolhidas que indicasse o significado da imagem.

A partir desses estímulos, o grupo seria convidado a manifestar sua opinião a respeito dos temas expostos, podendo essa dinâmica ser definida como um diálogo/debate em grupo, em que cada uma exporia o que pensava sobre determinado assunto, enquanto a moderadora estimularia que fossem expostas opiniões convergentes e divergentes sobre o que havia sido dito. Após essa explicação, as meninas também foram consultadas sobre seu consentimento na utilização de filmadora para gravar os encontros. Esclareceu-se que as discussões realizadas nos encontros com o grupo seriam gravadas em vídeo e que, posteriormente, todas as falas seriam transpostas em texto. Comunicou-se às meninas, ainda, que as informações da pesquisa seriam confidenciais e divulgadas apenas em eventos ou publicações científicas, não havendo identificação das participantes, a não ser entre os(as) responsáveis pelo estudo, sendo assegurado o sigilo sobre a sua participação. As meninas foram informadas, também, sobre os procedimentos éticos da pesquisa: seria preciso que um(a) dos(as) responsáveis por elas assinassem um termo de consentimento permitindo sua participação no estudo. Da mesma forma, elas precisariam assinar outro termo, de assentimento, demonstrando sua concordância em fazer parte da pesquisa.

O segundo encontro foi realizado com as mesmas meninas que participaram do primeiro encontro. A proposta do segundo encontro foi trazer selfies masculinas para propor às meninas que pensassem imagens de corpos masculinos em relação às imagens dos corpos femininos. Além disso, foram também apresentadas às meninas selfies de corpos que fogem aos padrões de gênero e de beleza hoje culturalmente sustentados, como corpos gordos e de mulheres com as axilas não depiladas, por exemplo. Ao levarmos tais imagens para discussão, o objetivo foi analisar as disputas e negociações travadas em torno da significação desses corpos e das classificações das zonas corporais que ganhavam destaque ou não nas imagens. Para este encontro, também foi proposto às meninas que trouxessem

\footnotetext{
${ }^{5}$ A seleção de todas as imagens que compuseram o conjunto de materiais organizados como disparadores das discussões foi feita por meio da ferramenta de busca do Google.
}

(C) ETD-Educação Temática Digital Campinas, SP $\quad$ v.20 $\quad$ n.4 $\quad$ p.1096-1116 out./dez. 2018 
em seus celulares duas selfies suas, uma de que gostassem e uma de que não gostassem, para problematizar as experimentações de si mediante a produção dos próprios corpos em imagem.

Já no último encontro, a proposta foi dar ênfase às formas de publicação, compartilhamento e vazamento de selfies consideradas eróticas ou sensuais. Para isso, foram levados alguns materiais que funcionaram como deflagradores da discussão: informações sobre o site "I shotmyselfie", que hospeda álbuns de selfies eróticas; uma música de MC Biel, intitulada "Selfie pelada", em cuja letra o cantor relata que recebe selfies de meninas peladas; um vídeo disponível na plataforma YouTube sobre o vazamento de fotos íntimas da atriz Jennette McCurdy, que ficou famosa na série de televisão iCarly; reportagens sobre o roubo de fotos íntimas da atriz Carolina Dieckmann; e, por último, foram mostrados às meninas dois Projetos de Lei, então em tramitação no Senado Federal, que propunham tornar crime a divulgação indevida de material íntimo.

Durante todo o processo de planejamento dos encontros de discussão, estiveram presentes questões éticas, pois, em algumas imagens de selfies mostradas às meninas, em espaço escolar, haveria utilização de imagens de seminudez. Assim, algumas inquietações surgiram: como discutir sobre selfies sensuais sem mostrá-las para deflagrar a discussão? E, no caso de mostrá-las, onde obtê-las? Como mostrá-las sem expor as protagonistas da imagem? Como discutir a produção e o envio de imagens sensuais com as meninas sem que elas se armassem com discursos politicamente corretos?

A partir das inquietações que surgiram durante o processo de realização da pesquisa, percebemos que uma relação ética consistente entre pesquisador(a) e participantes é estabelecida durante o processo de pesquisa. É na resolução de preocupações e impasses que precisa haver uma constante negociação entre pesquisador(a) e participantes, no sentido de explorar as possibilidades inerentes a cada desenho metodológico de pesquisa, respeitando os limites de todos(as) os envolvidos(as). Dessa maneira, algumas das questões éticas prementes foram negociadas com as meninas no decorrer dos encontros de discussão. Graças a essas negociações, optou-se por não utilizar imagens de nudez explícita, já que estávamos realizando os encontros em ambiente escolar e com meninas que, diante da lei, eram menores de idade. Deu-se, então, ênfase às imagens de selfies nas quais os corpos estavam na fronteira entre o sensual e o erótico (o sexy).

É importante frisar que, embora não tenhamos operado com imagens nas quais os corpos estivessem em poses explícitas - como, por exemplo, mostrando ou tocando os órgãos genitais -, as próprias meninas trouxeram a discussão sobre a nudez, os limites entre as selfies pornográficas ou eróticas e o seu vazamento ou compartilhamento involuntário. Em diversos momentos dos encontros, elas descreveram fatos que aconteceram com

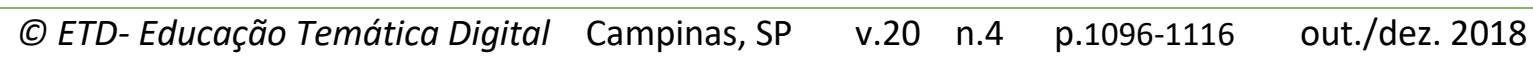


meninas da convivência de cada uma delas, algumas, inclusive, também estudantes da Escola onde se realizou esta pesquisa. Nesses comentários e relatos, às vezes ocorridos em conversas paralelas à discussão do grande grupo, as meninas falaram sobre a produção e o compartilhamento deste tipo de selfie, disputando e significando esta prática.

A preocupação ética no campo em que se insere esta pesquisa vai além de trâmites formais e burocráticos, mas necessários para o desenvolvimento de estudos com seres humanos. Assumimos que a ética de pesquisa com seres humanos não é algo garantido de uma vez por todas mediante aprovação de um CEP, mas que é uma relação singular que se estabelece no cotidiano da pesquisa entre pesquisador(a) e pesquisados(as) (ZAGO; GUIZZO; SANTOS, 2016; DINIZ, 2010; MULLER; INSTONE; 2008). Nesse sentido, cabe aqui a menção (ética e metodológica) de que as falas das meninas emergiram em um contexto específico o grupo de discussão -, o que nos leva a sugerir que já havia uma regulação, no momento mesmo da produção dos dados, acerca daquilo que as próprias meninas acreditavam ser possível dizer e ver sobre o tema proposto. Isto é, o fato de as participantes estarem em grupo, e não sozinhas (como seria o caso no emprego de outro método, como o de entrevista semiestruturada), estabeleceu limites sobre o dizível e o visível que funcionaram como balizadores dos dados.

\section{PEDAGOSELFIES: UMA PEDAGOGIA DO CORPO FEITO EM IMAGEM}

A experiência de tornar o corpo uma imagem é um dos efeitos dos modos de vida contemporâneos que têm colocado o corpo em um lugar central na vida de cada um de nós, lugar este privilegiado para obtenção de prazer e satisfação (COSTA, 1998; ORTEGA, 2005). Investir no próprio corpo, na busca de torná-lo mais potente, saudável e atraente, é uma preocupação que arregimenta fortemente os indivíduos deste tempo. Aliadas a essa centralidade, as tecnologias digitais de comunicação, como os smartphones, proporcionam novos modos de organização e interação social (SIBILIA, 2016). Nesse sentido, as tecnologias digitais vêm transformando profundamente as formas como produzimos imagens, especialmente aquelas cujo objeto fundamental é o corpo e, mais especificamente, aquelas imagens dos corpos que são publicadas em redes sociais on-line. É nesse contexto social que os modos de produção de imagens dos corpos dos indivíduos se tornam tão relevantes.

Talvez a imagem do corpo não seja mais importante do que sua materialidade orgânica, mas evidentemente é parte do conjunto de representações dos corpos contemporâneos. A imagem de um corpo é quase uma extensão de sua materialidade pouco vale "ter um corpo" se ele não pode ser mostrado e reconhecido pelo olhar do outro. Pouco adianta ser belo(a) se não souber "imprimir-se" em imagem para que o corpo possa ser olhado e admirado por vários olhares curiosos - e julgadores. Pouco adiantam investimentos de tempo, sacrifícios, dores e dinheiro no corpo - como nas academias de

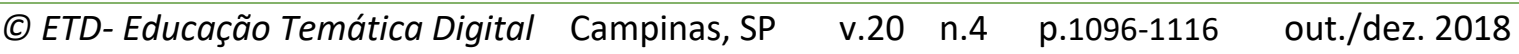


musculação, nas mesas de cirurgia plástica e em dietas severas - se não for possível exibi-lo (SOARES, 2009; SANT'ANNA, 2005). Dessa maneira, assim como é preciso saber cuidar do corpo, é também preciso saber torná-lo imagem exibível. E aprender a tornar o corpo uma imagem exige uma série de habilidades que precisam ser ensinadas, aprendidas, testadas e exercitadas muitas vezes: a esse processo, chamamos de pedagoselfie.

Propomos que a produção de imagens de si, na forma de autorretratos, é uma prática que põe em funcionamento certa pedagogia hoje presente na cultura ocidental, entendendo por pedagogia, de modo amplo, as complexas práticas e experiências que ensinam determinadas maneiras de constituir-se sujeito no tempo presente (COSTA; SILVEIRA, SOMMER, 2003). A noção ampliada de pedagogia permite-nos nomear o conjunto de práticas empregadas pelas meninas participantes dos grupos de discussão para produzirem imagem de si como relações de ensino-aprendizagem que se referem a cuidados e táticas intrínsecos às formas como elas se colocam e se veem no mundo. Assim, o neologismo pedagoselfie é uma tentativa de destacar os vínculos existentes entre a produção de selfies, tão comum entre usuários(as) de redes sociais na atualidade, e sua associação com a cultura e com as normas corporais atuantes na nossa sociedade. Portanto, a produção de imagens de si ganha forma e sentido por meio de um processo cotidiano e informal de ensino-aprendizagem, articulando o uso de tecnologias digitais, redes sociais on-line e padrões estéticos que constituem o regime de visibilidade aceito por uma parcela da juventude brasileira. Logo, propomos que uma determinada pedagogia esteja em operação, marcando, instituindo, ensinando e organizando os significados das práticas de produção de selfies entre o grupo de meninas participantes da pesquisa - significados esses para os quais convergem corpo, imagem e tecnologia.

Paula Sibilia (2004, p. 68) chamou de "design epidérmico" as múltiplas estratégias pelas quais o corpo é submetido para o cultivo das "boas aparências", em um tempo em que "a visibilidade e o reconhecimento no olhar alheio são fundamentais na definição do que cada um é". No cerne desse enaltecimento do corpo e da valorização da aparência, a autora ressalta que se ergue um paradoxo: enquanto delegamos ao corpo o lugar de maior valor na determinação de quem somos, "o corpo é desprezado com uma violência inédita" (SIBILIA, 2004, p. 68). Ela analisa o modo como o corpo orgânico - com todas as suas células, órgãos, tecidos, etc. - vem sendo cada vez mais rejeitado pelas sociedades ocidentais a partir do início deste século (SIBILIA, 2004). Em uma época em que a abundância, o desperdício e os excessos estão em alta, o medo da fome vem sendo substituído pelo pavor da obesidade, na mesma proporção em que as aparências corpóreas parecem determinar as realidades psíquicas interiores de cada indivíduo. Nesse contexto, não para de crescer a oferta de produtos, serviços e profissionais que se dedicam a desenvolver técnicas e produtos para interferir na aparência do corpo. Da indústria farmacêutica à indústria de
(C) ETD- Educação Temática Digital
Campinas, SP
v.20 n.4
p.1096-1116
out./dez. 2018 
cosméticos, das academias de musculação às clínicas de beleza, o objetivo parece ser o mesmo: purificar o corpo dos excessos e das imperfeições impostas por sua condição orgânica (SIBILIA, 2004).

Sibilia (2004) propõe que tem se consolidado culturalmente um modelo corporal hegemônico que busca uma "pureza digital", emergente graças aos variados recursos tecnológicos voltados para produção e edição gráfica dos corpos feitos em imagem. Em um mundo dinamizado pela proliferação de imagens de todos os tipos, nossos olhos aprendem - com a mídia, com a publicidade, com o marketing pessoal dos(as) famosos(as) e das pessoas "comuns" - padrões de beleza e de feiura. O corpo purificado pela imagem, ou seja, o corpo remodelado, retocado, potencializado e livre das impurezas orgânicas, alcança certo status de perfeição, organizando nosso imaginário e conduzindo-nos, às vezes de formas pouco sutis, ao sacrifício diário de busca de adequação a esse modelo corporal puro e belo. No universo feiticeiro das imagens dos corpos, onde todo defeito pode ser escondido, apagado ou editado, peles lisas, cabelos sedosos e corpos curvilíneos brilham e ofuscam toda matéria orgânica, cujo indelével destino leva às rugas, à gordura, às sobras de pele e ao envelhecimento.

Gilles Lipovetsky e Jean Serroy (2015) realizaram uma instigante investigação sobre a maneira como o mercado de produção, distribuição e consumo vem sendo remodelado a partir de imperativos estéticos. Segundo os autores (2015, p. 13),

[...] estamos no momento em que os sistemas de produção, de distribuição e de consumo são impregnados, penetrados, remodelados por operações de natureza fundamentalmente estética. $O$ estilo, a beleza, a mobilização dos gostos e das sensibilidades se impõem cada dia mais como imperativos estratégicos das marcas: é um modo de produção estético que define o capitalismo de hiperconsumo.

Assim, estaríamos vivendo um período em que as forças capitalistas se utilizam do potencial criativo dos sujeitos e da mobilização de sensibilidades para disseminar valores artísticos e estéticos, para produzir cultura e entretenimento, moda e estilos, gostos e desejos. Não menos racionais e vorazes do que no capitalismo industrial, as forças do capitalismo-artista buscam lucro mediante estratégias que se valem dos gostos e das emoções pessoais de cada sujeito. Por isso, os autores sugerem que "estamos num novo ciclo marcado por uma relativa desdiferenciação das esferas econômicas e estéticas" (LIPOVETSKY; SERROY, 2015, p. 14).

Neste período de estetização do mercado e da vida, multiplicam-se, sem cessar, os espetáculos, as tendências, as modas, os locais da arte e os estilos individuais, estimulando a produção de subjetividades que levam os indivíduos a investir em si, por meio de seus gostos e preferências (LIPOVETSKY; SERROY, 2015). A nova dinâmica social, pautada em valores estéticos, além de despertar o gosto pela moda, pela música, pelos espetáculos,

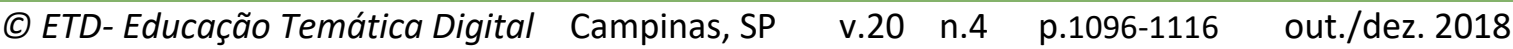


pelo turismo e pela fotografia, produz uma forte tendência entre os indivíduos: estilizar tudo que está à sua volta, inclusive a própria carne. O local de trabalho, a casa, o carro, os objetos pessoais, as roupas, as páginas nas redes sociais e os próprios músculos e contornos dérmicos do corpo devem dizer sobre quem somos. Ou seja, tudo aquilo que é visível deve estar de acordo com nossa personalidade e estilo, ou melhor, deve produzir/marcar uma personalidade e um estilo próprio. Portanto, pauta-se a produção de subjetividades em conformidade com os padrões estéticos vigentes em nossa cultura.

Com a inflação da oferta consumatória, os desejos, os olhares, os juízos propriamente estéticos se tornaram fenômenos presentes em todas as classes sociais ao mesmo tempo que tendem a se subjetivizar. O consumo com componente estético adquiriu uma relevância tal que constitui um vetor importante para a afirmação identitária dos indivíduos. Coisa cotidiana, o consumo transestético atinge em nossos dias quase todos os aspectos da vida social e individual: à medida que recua a ascendência dos imperativos de classe, comer, beber, vestir-se, viajar, morar, ouvir música, tudo se torna uma questão de gostos subjetivos, de emoções pessoais, de opções individuais, de preferências mais ou menos heterogêneas: é uma estética autorreflexiva que estrutura o consumo hiperindividualista. (LIPOVETSKY; SERROY, 2015, p. 30-31)

Ser igual, mas ser diferente: eis um paradoxo e também um desafio para os indivíduos deste tempo. No nosso presente, em que a estética parece perpassar todas as esferas da vida, até mesmo nossas carnes, é preciso saber gerenciar sua personalidade com estilo e "bom gosto". Tudo o que somos e tudo o que fazemos precisa ser "apresentável", aprazível esteticamente ao olhar dos outros. É preciso mostrar, naquilo que somos, naquilo que fazemos e nos objetos que possuímos, todas as nossas emoções, preferências, desejos, sonhos, experiências individuais e todas as nossas singularidades, aquilo que nos diferencia, que nos torna únicos(as), diferentes. Porém, conforme mostraremos a seguir, toda produção estética individual, que certamente desemboca nos nossos próprios corpos, não pode estar em desacordo com certos padrões mais ou menos operantes na nossa cultura e compartilhados pelas jovens meninas. As marcas de singularidade devem diferenciar-nos dos(as) demais sem que causem muita estranheza: as singularidades têm de ser agradáveis aos olhos de quem as vê, em especial aquelas que são, literalmente, in-corporadas.

Paula Sibilia (2004; 2016), ao analisar a forma como as subjetividades se transformaram ao longo do último século, acompanhando o universo tecnocientífico, propõe o seguinte:

Em meio aos vertiginosos processos de globalização em uma sociedade altamente midiatizada, fascinada pela incitação à visibilidade e pelo império das celebridades, percebe-se um deslocamento daquela subjetividade "interiorizada" em direção a novas formas de autoconstrução. No esforço de compreender esses fenômenos, alguns ensaístas aludem à sociabilidade líquida ou à cultura somática do nosso tempo, onde aparece um tipo de eu mais epidérmico e flexível, que se exibe na superfície da pele e das telas. Referem-se também às personalidades alterdirigidas

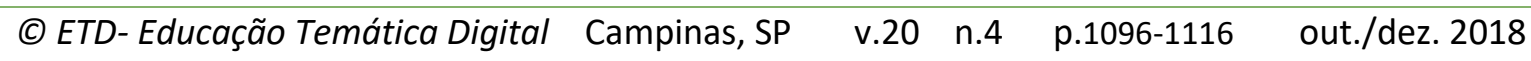


e não mais introdirigidas, construções de si orientadas para o olhar alheio ou "exteriorizadas", não mais introspectivas ou intimistas. (SIBILIA, 2016, p. 48)

Nesse processo de construção do eu - nunca fixo e estável -, a interioridade, o autoconhecimento, o voltar-se para si mesmo na busca de um eu centrado, introspectivo e, portanto, misterioso, foram paulatinamente perdendo força e sentido em um contexto social em que as tecnologias de nossa época propiciam que (quase) tudo seja transformado em imagem e que (quase) todos(as) estejam conectados(as) em redes sociais on-line. Em tempos de popularização da internet como meio de comunicação, somos levados(as) a crer que tudo e todos(as) precisam ser visíveis - eis o imperativo do "totalitarismo fotogênico" (SANT'ANNA, 2005, p. 107). É assim que a construção das subjetividades alterdirigidas, voltadas para o olhar do outro, de que trata Sibilia (2016), faz tanto sentido nos dias de hoje.

Sant'Anna (2005, p. 106) argumenta que, na ordem tecnocientífica-empresarial que vem se desenvolvendo nos últimos anos, se aprofunda uma tendência em torno da exposição do corpo, que é a de utilizá-lo como uma importante ferramenta de "marketing privilegiado do eu". De acordo com essa tendência, cada parte do corpo é transformada em "imagem de marca", a qual deve ser preparada cuidadosamente para ser vista, admirada, filmada e fotografada. Segundo Sant'Anna (op. cit. p. 107, grifo da autora) "há, aqui, uma espécie de totalitarismo fotogênico banalizado: exige-se que tudo no corpo seja preparado para ser visto, exposto, colocado em pose".

No rastro do pensamento de Sant'Anna (2005), nessa nova política de exposição do corpo que fundamenta o que ela chama de "marketing do eu", colocar o corpo em pose para que funcione como "imagem de marca" envolve a operação de pedagoselfie. Essa tendência de transformar tudo em imagem, inclusive a nós mesmos(as), estimula que saibamos estar sempre prontos(as) para tornarmo-nos uma foto. A transformação operada no corpo no momento de fazer uma foto é produzida utilizando-se diversas estratégias, que são aprendidas desde muito cedo pelos sujeitos que vivem neste tempo.

\footnotetext{
"Ser fotogênico ou não ser", eis o lema desta demanda por exposição do corpo. Como se não fosse desejável relegar nenhuma zona física à sombra. Esta tendência ganhou uma amplitude impressionante durante as duas últimas décadas. Há uma multidão de corpos que parecem estar literalmente sob o sol do deserto, sem abrigo, sem segredo, sem diferença entre o lá e o aqui, esturricados pela exposição midiática, destituída de pausa. (SANT'ANNA, 2001, p. 67)
}

Conforme a mesma autora (SANT'ANNA, 2001, p. 67), as campanhas publicitárias não cessam de multiplicar imagens nas quais as partes mais íntimas do corpo são expostas despudoramente. Porém, com um detalhe importante: devem estar tratadas e embelezadas. À medida que o corpo feminino foi ganhando maior liberdade para mostrar-se e expressar-se, maiores foram se tornando as exigências em torno dos cuidados voltados a ele. Sant'Anna (2001, p. 66, grifo da autora) argumenta que "a vontade de ser mulher livre

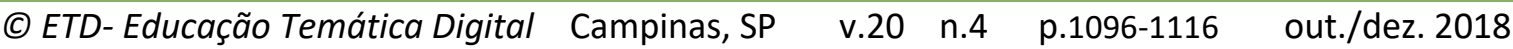


rima com o dever de ser fotogênica para os outros e para si mesma, em todas as circunstâncias".

Se todos os objetos são passíveis de serem transformados em imagem para que possam ser vistos, o mesmo pode acontecer com nosso corpo. Constituímos nossas noções do eu a partir de nosso olhar sobre nossas próprias imagens, mas também a partir do olhar do outro sobre nós, sobre nossos corpos. Se, até pouco tempo atrás, as referências que tínhamos para construirmos uma noção de nossa própria imagem eram, em especial, o pálido reflexo que víamos no espelho, ou algumas linhas e volumes em preto e branco sobre o papel, ou aquilo que se dizia sobre nós, hoje, por outro lado, temos um elemento a mais para a composição imagética da noção de quem somos. Esse elemento é a fotografia digital. O grande número de fotografias que produzimos de nós mesmos, especialmente graças à popularização das câmeras acopladas aos smartphones, gera efeitos nas maneiras como percebemos e construímos nossa própria imagem. Por essa razão, transformar o corpo em uma "boa imagem" torna-se uma prática importante e, ao mesmo tempo, difícil para os indivíduos deste tempo, uma vez que esta imagem diz e mostra "quem somos" e "como estamos" não só aos outros, mas a nós mesmos(as).

\section{O CORPO COMO IMAGEM SOB O OLHAR DO OUTRO}

As meninas discutiram, a certa altura de um dos encontros, a importância das curtidas nas fotos que elas publicam - que, segundo Elisa, "sempre dá uma mexida no psicológico" " . Isso porque as curtidas nas imagens do corpo são um aspecto relevante do processo da pedagoselfie: atestam a vigência do olhar escrutinador e julgador do outro. Apesar de as meninas dizerem que as curtidas "não têm tanta importância assim" (Elisa), elas também ressaltam que o número de curtidas produz efeitos na forma como elas interpretam as imagens de si. As curtidas servem como um termômetro que mede o grau de aprovação de tudo aquilo que é publicado nos perfis das redes sociais. Por isso, como disse Elisa: "Tu tiraste uma selfie e achaste bonita. Aí, postaste, e cinco pessoas curtiram. Tu vais achar que estás feia na foto, porque ninguém curtiu". Por outro lado, se houver muitas curtidas, "tu vais achar que estás linda", disse Sophia em um dos encontros.

Os argumentos das meninas sobre a importância das curtidas mostram as tensões e negociações que envolvem produzir o corpo como imageticamente relevante e expô-lo ao olhar do outro. Enquanto se estimula que sejam assumidas personalidades autênticas e singulares, teoricamente autossuficientes e independentes da opinião alheia, a exposição constante ao olhar desse outro e a maneira tirânica como somos subjetivados a investir no corpo e na aparência fazem com que precisemos reconhecer-nos nesse olhar de radical

\footnotetext{
${ }^{6}$ Trechos curtos de falas são incorporados no texto entre aspas e em itálico para melhor identificação.

(C) ETD-Educação Temática Digital Campinas, SP $\quad$ v.20 n.4 $\quad$ p.1096-1116 out./dez. 2018
} 
alteridade para sentirmo-nos aceitos(as) e valorizados(as). Logo, a possibilidade de curtir e comentar nos conteúdos publicados nas redes sociais, como o Facebook, é condizente com as novas dinâmicas de interação social no ambiente midiático e, sobretudo, responde a uma forte necessidade de mostrarmo-nos e expressarmo-nos. A possibilidade de interação que as curtidas e os comentários proporcionam nas redes sociais faz dessas duas funções partes importantes do processo da pedagoselfie, haja vista que o processo de ensinoaprendizagem do ato de tirar uma foto de si e publicar nas redes sociais inclui o sucesso imagético desse corpo que, de orgânico, se torna editável, publicável, pixelado literalmente, convertido em pixels. E o sucesso ou não do corpo feito em imagem pode ser quantificado pelas curtidas que a fotografia recebe, uma vez publicada nas redes sociais.

Entretanto, o julgamento do olhar do outro guarda suas contradições, principalmente quando esse "outro" é "outra" conhecida pessoalmente - isto é, uma amiga da rede de sociabilidade pessoal. As meninas ressaltaram que o número de curtidas interfere na forma como elas avaliam suas próprias imagens, mas explicaram que o mesmo não acontece no seu julgamento em relação às imagens produzidas de outras meninas. Podemos perceber isso nas seguintes falas, encadeadas nesta sequência: (Elisa): "Se tu viste uma pessoa e achaste feia e ela tem 4.000 curtidas, tu vais continuar achando ela feia; se tu achares uma foto bonita, e a pessoa tem 20 curtidas, tu vais continuar achando ela bonita"; (Antonela): "Claro, porque tu sabes como é que ela é pessoalmente". Nesse caso, as meninas afirmaram que o alto número de curtidas, ou o reduzido número de curtidas, não determina necessariamente se a pessoa é linda ou feia: o que irá determinar tal classificação é a forma como a pessoa é pessoalmente, isto é, fora das redes sociais.

A exigência de tornar visível tudo aquilo que define nossa singularidade faz com que a produção e a seleção das fotografias que serão expostas aos olhares alheios sejam uma tarefa minuciosa e de muito valor - embora não seja compulsória. Observemos o seguinte excerto:

Elisa: A [Amiga] tem vinte fotos por dia no Instagram.

Julia: Eu vejo todo dia que ela posta uma ou duas.

Isabela: Eu não consigo ser assim.

Carolina: Eu também não.

Elisa: Até porque eu nem tiro foto todos os dias.

Isabela: Não é todo dia que eu me acho bonita. É raramente que eu me acho bonita.

Rafa: Na real, eu só tiro foto quando eu estou arrumada pra sair pra festa, sabe? Porque, dia a dia, é difícil eu tirar foto. ${ }^{7}$

\footnotetext{
${ }^{7}$ Trechos longos de falas são destacados do texto, dentro de caixas de texto, em itálico e espaço 1 para melhor identificação.

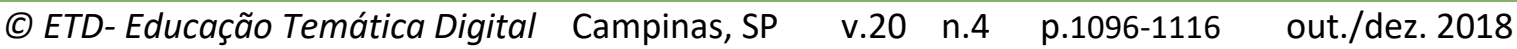


Quando as meninas afirmam que uma selfie é feita quando acreditam que estão bonitas ou quando estão arrumadas para alguma festa, podemos pensar que essa prática indica preocupação em mostrar a melhor versão que elas podem produzir delas mesmas. Nesse caso, a produção do corpo em imagem possibilita o registro, a montagem e a edição de versões ideais de si, em momentos singulares. São possibilidades que só existem na versão digitalizada e imagética dos corpos, isto é, não se trata da produção de uma imagem absolutamente banal. Conforme mostram as falas das meninas, é necessário haver uma atenção ao corpo e ao momento específico em que se pode produzir uma selfie - como sugere Isabela, "não é todo dia que me acho bonita. É raramente que eu me acho bonita". Retomando Sibilia (2016), vivemos um tempo em que as tecnologias da comunicação e informação têm feito proliferar "festivais de vidas privadas". Esse interesse pelo ordinário, pelo corriqueiro, pela pequenez da vida cotidiana - a curiosidade pelo que de mais íntimo se pode expor, em especial, sobre a vida das celebridades do momento -, chama os indivíduos a exercerem a tarefa de narradores de suas próprias vidas. Entretanto, a consideração de que não se pode (ou não se deve) produzir uma imagem de si a qualquer momento, conforme as falas de Isabela, Carolina e Elisa, destacadas no trecho anterior, oferece a possibilidade de relativizarmos o "totalitarismo fotogênico" proposto por Sant'Anna (2005, p. 107). As meninas afirmam que, embora sejam usuárias assíduas de redes sociais e se engajem na produção de selfies, a produção e divulgação das imagens de seus corpos não é vista como uma obrigação. Ainda, Rafa sugere que existe uma correlação entre a produção de imagens de si e eventos da sua vida cotidiana quando diz "eu só tiro foto quando eu estou arrumada pra sair pra festa, sabe?". Pode-se assinalar, por isso, um tensionamento em relação ao argumento de Sibilia (2016) acerca do "show do eu" e da construção autônoma de vidas imagéticas on-line, quase desconectadas do cotidiano não mediado pelas redes socais. Essa fala sinaliza, também, o fato de que a preparação do corpo feito posteriormente - em imagem não se limita à imagem em si, mas está atrelada à possibilidade de uso de determinadas roupas para ocasiões especiais. Tensiona-se, assim, a tirania da fotogenia, pois as meninas mostram que há limites compartilhados por elas acerca da pertinência de fazer imagens de seus corpos.

Como podemos ver no trecho a seguir, a produção de imagens de si caracteriza a articulação entre as possibilidades das tecnologias digitais e determinado regime de visibilidade, que faz passar a experiência contemporânea dos corpos pelo registro imagético. As narrativas pessoais imagéticas produzidas nas redes sociais on-line possibilitam que os indivíduos (em especial, as jovens meninas participantes da pesquisa) utilizem variados recursos para a produção de versões específicas de si mesmos e de seus corpos, que, necessariamente, precisam estar a contento das normas regulatórias que constrangem sua exposição e sua apresentação.
(C) ETD- Educação Temática Digital
Campinas, SP
v.20 n.4
p.1096-1116
out./dez. 2018 
Elisa: Acho que ninguém usa Photoshop aqui. É só filtro ${ }^{8}$ mesmo.[...]

Pesquisadora: E, além do filtro, sobrancelha, cílios, recorte, o que mais que vocês costumam fazer?

Sophia: Filtro todo mundo usa, mas não bota...

Isabela: Mas as outras coisas, nunca.

Sophia: Acho que todas as fotos que a gente posta é com filtro pra dar um contraste ou coisa assim.

Carolina: Às vezes, é bem suave... Às vezes, mal dá pra ver a diferença, mas, mesmo assim, eu posto a que está com filtro, porque eu acho melhor a que está com filtro [risos].

A edição das imagens é uma prática tensionada entre as meninas, pois, como mostram as falas, elas disputam quais os limites que devem ser respeitados na hora de editar uma imagem. É uma prática de comum acordo entre elas o uso do filtro, recurso utilizado para retocar e melhorar as fotos, com efeitos que incluem a modificação de cores, iluminação, foco, brilho e exposição à luz da imagem produzida. Entretanto, apesar de serem a favor da aplicação dos efeitos de edição oferecidos pelos filtros, elas parecem rigorosas quanto à utilização do Photoshop - como se a utilização desse famoso software de imagens fosse um instrumento "altamente invasivo" no corpo imagético. As falas das meninas mostram que elas estabelecem uma diferença entre os recursos tecnológicos disponíveis para transformar as imagens de seus corpos: para elas, o Photoshop distorce a imagem e, assim, a própria realidade, pois é utilizado para colocar sobrancelhas e cílios postiços, para aumentar ou diminuir partes do corpo, para fazer desaparecer imperfeições dérmicas, espinhas, manchas, cicatrizes ou tatuagens; já o filtro não interfere no corpo imagético a ponto de retirar ou acrescentar qualquer elemento corpóreo registrado, mas apenas potencializa traços que já existem na imagem, sem necessariamente transformá-la: supostamente, o filtro apenas "filtra", ao passo que o Photoshop "distorce". Subsiste, assim, a crença em uma carne orgânica do corpo, cuja imagem precisa corresponder à referência "real". Nesse sentido, o corpo editado é aquele corpo imageticamente privilegiado, potencializado em seus aspectos "reais", corpo que figura em uma selfie enquanto uma imagem realçada; o corpo editado é a carne filtrada em imagem. O corpo editado é diferente do corpo photoshopado, pois este último se torna outro corpo, cuja referência à "realidade" se perdeu pelo acréscimo ou supressão de marcas que lhe são, aparentemente, intrínsecas. Dito de outro modo, esse corpo seria uma farsa.

\footnotetext{
${ }^{8}$ Filtro é um recurso encontrado em aplicativos que oferece modelos/estilos de imagens com cores e efeitos diferenciados, os quais podem ser aplicados automaticamente na imagem submetida. O filtro é um recurso. Creio que a lista do que ele possibilita tem a ver com efeitos. Na página seguinte, há uma exemplificação dos efeitos possibilitados pelos filtros. Sugiro retirar a parte em verde.
}

(C) ETD-Educação Temática Digital Campinas, SP $\quad$ v.20 $\quad$ n.4 $\quad$ p.1096-1116 out./dez. 2018 
Enquanto houve reprovação dos recursos de "interferência da realidade" por meio do Photoshop, a utilização do filtro parece ser uma regra aceitável entre as meninas participantes da pesquisa, como podemos ver na fala de Sophia: "Filtro todo mundo usa [...] Acho que todas as fotos que a gente posta é com filtro pra dar um contraste ou coisa assim". É possível que, conforme assinalado na seção metodológica deste artigo, a censura sobre o uso do Photoshop para intervir de modo radical nos autorretratos e a correspondente condescendência na utilização de filtros nas imagens possam ser oriundas da própria regulação que o método de grupo de discussão trouxe à pesquisa. É possível que as jovens meninas eventualmente façam uso de alguma técnica ou tecnologia de intervenção radical nas suas selfies, mas a admissão de tal prática dentro do espaço do grupo de discussão poderia estar temporariamente suspensa graças à regulação pelo olhar do(a) outro(a), que acontecia, inclusive, por ocasião da própria produção dos dados da pesquisa. Inobstante, podemos sugerir que a pedagoselfie abrange a expertise em produzir o próprio corpo em imagem, que envolve o domínio técnico e cultural do processo, o que vai desde a captura da imagem até os retoques finais de edição com o uso de filtros e sua possível publicação. Conforme disse Carolina sobre a aplicação de filtros em suas selfies: "Às vezes, é bem suave. Às vezes, mal dá pra ver a diferença, mas, mesmo assim, eu posto a que está com filtro, porque eu acho melhor a que está com filtro". Assim, o filtro serve como uma purificação imagética da realidade do corpo, condizente com o que Sibilia $(2004$, p. 68) chama de "design epidérmico" dos corpos feitos em imagem. O filtro não altera a imagem, não a "falsifica", apenas a melhora.

A fala de Antonela, destacada abaixo, tematiza a possibilidade de apagar a imagem de si publicada em redes sociais caso não se obtenha um número significativo de curtidas, pois isso demonstraria que a imagem não causou o efeito esperado ou que não foi bem aceita:

Elisa: Que nem falou a Antonela, se tu viste uma pessoa, achaste feia, e ela tem 4.000 curtidas, tu vais continuar achando ela feia. Mas tipo, tu tiraste uma selfie e achaste ela bonita. Aí, postaste, e cinco pessoas curtiram, tu vais achar que estás feia na foto, porque ninguém curtiu, entendeu?

Antonela: Tu vais apagar a foto. Mais ou menos isso.

Elisa: É, não sei se tu vais apagar, mas, querendo ou não, sempre dá uma mexida no psicológico da gente.

Carolina: É.

Antonela: A gente se importa. Um pouco, mas se importa.

A possibilidade de excluir, deletar, fazer sumir do campo do visível a imagem que não obteve uma aprovação mensurável, a julgar pelo número de curtidas que recebe, só existe para o corpo feito em imagem. Diferentemente do corpo orgânico, o corpo editado $e$ editável pode ser publicado e excluído quantas vezes forem necessárias em decorrência dos

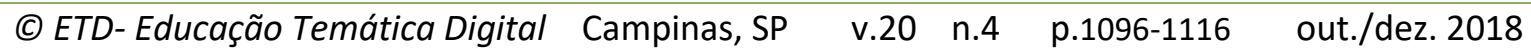


julgamentos do outro. Se receber muitas curtidas, é sinal de que a imagem de si está adequada ao julgamento alheio; se o número de curtidas for abaixo do esperado pela autora da imagem, pensa-se que tal imagem de si é inadequada à norma estética - e, portanto, merece ser eliminada. O processo de ensino-aprendizagem da pedagoselfie inclui a negociação, e eventual concordância, com as normas estéticas que regulam a exibição imagética da carne: as meninas mostram que aprenderam a produzir uma bela imagem dos seus corpos - mesmo que seus corpos não sejam exatamente belos - porque podem editálos e melhorá-los enquanto imagem, depois podem publicá-los e, além de tudo isso, podem avaliar seu grau de aprovação. Se for necessário, as meninas mostraram que também é possível deletar os corpos, apagá-los do campo do visível, caso não lhes for conferido o reconhecimento por elas esperado: essas são as características do corpo editado e editável.

Como foi possível perceber a partir das falas apresentadas anteriormente, as possibilidades que o conjunto das tecnologias digitais oferece para a experiência do corpo no tempo presente açambarcam sua filtragem imagética com vistas à purificação das imperfeições que a condição orgânica lhe impõe (SIBILIA, 2004). Ainda, segundo as falas das meninas participantes da pesquisa, é preciso considerar que tal purificação imagética está intrinsecamente atrelada a pelo menos dois aspectos: primeiro, o reforço da atuação insidiosa de certas normas regulatórias de exibição dos corpos que, por meio de "pedagogias totalitárias", visam a transformá-los em "esculturas de carne" (SOARES, 2009) ou, no nosso caso, em imagens editadas de carne; segundo, a circunscrição de um regime de visibilidade singular do tempo presente (BRUNO; KANASHIRO; FIRMINO, 2010), constantemente modulado e negociado pelos indivíduos mediante a exposição da imagem de si ao outro, cujo escrutínio visual baliza a produção, edição e publicação de selfies em redes sociais on-line.

Durante diferentes momentos dos três encontros de discussão com o grupo de meninas, elas ressaltaram a existência de estratégias que visam a tornar o corpo uma imagem, e uma "boa imagem". Para fazer da carne uma boa imagem, segundo as meninas, é preciso ensaiar seu melhor ângulo e a pose que lhe favorece, saber quais partes do corpo devem ser escondidas e quais devem ser destacadas, quais recursos de edição são aceitos e quais são reprovados; sobretudo, é a expectativa do olhar do outro sobre a imagem de si que é reguladora de todo o processo de produção da selfie. São justamente essas estratégias que são ensinadas e aprendidas ao longo da experiência de cada indivíduo com a produção, edição e publicação do próprio corpo em imagem, o que chamamos de pedagoselfie.

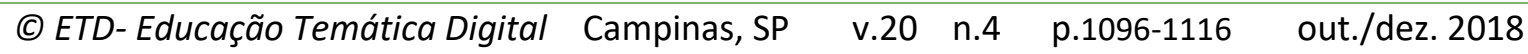




\section{CONSIDERAÇÕES FINAIS}

Analisando a produtividade do termo pedagoselfie e das práticas às quais ele se refere para a transformação do corpo em imagem, percebemos que os significados em torno de tal prática e a forma de exercê-la são constantemente ensinados, aprendidos, disputados e negociados entre as meninas participantes da pesquisa. Por meio de múltiplas contradições e negociações, as meninas mostraram como o olhar do outro importa para a produção do corpo como imagem. Dito de outro modo: podemos sugerir que o olhar do outro funciona como um espelho que não apenas reflete o que somos, mas constitui a própria relação por meio da qual nossas subjetividades são produzidas. As falas das meninas permitem-nos entrever também que o domínio de técnicas e de certas habilidades no manejo de aparatos tecnológicos possibilitam que um corpo orgânico não tão belo seja produzido/transformado em belas imagens mediante o processo que chamamos de pedagoselfie.

Esse processo, que envolve aprender ou não a produzir/transformar o corpo em imagem, torna-se importante, na medida em que o olhar do outro se torna central para a definição de nossas subjetividades. De acordo com os aportes de Sibilia (2016), em um tempo em que a centralidade das redes sociais on-line se sustenta graças às subjetividades alterdirigidas imageticamente construídas, a definição de quem somos está estreitamente ligada ao reconhecimento e à valorização do olhar alheio em face das imagens de si que produzimos e publicamos. Dessa forma, as tecnologias digitais e as redes sociais são importantes ferramentas para nossa vida social. Consideramos, contudo, que as redes sociais e as tecnologias de produção de imagem operam precisamente na interface entre a experiência da vida cotidiana e a construção de vidas imagéticas: o corpo feito em imagem encontra um limite na própria manipulação das fotografias. As jovens meninas participantes desta pesquisa censuram as versões dos corpos-pixel exageradamente photoshopadas, a ponto de perderem seu referente "real", isto é, o corpo desligado das redes sociais. O sucesso ou não de tais versões imagéticas dos corpos depende, entre outras coisas, das competências desenvolvidas pelos sujeitos para a produção/transformação do seu corpo em imagem e, igualmente, do respeito a certos limites, como esse recém-mencionado. $O$ desenvolvimento das técnicas e habilidades necessárias faz parte de uma pedagogia voltada para a produção de selfies, que foi nomeada neste estudo como pedagoselfie, porque como destacaram as meninas ao longo dos encontros de discussão - ninguém nasce sabendo fazer selfies. Ou seja, trata-se de um processo complexo, que precisa ser aprendido mediante inúmeras tentativas, sempre considerando as expectativas da alteridade.

Acreditamos ser o aspecto pedagógico, que envolve o ensinar e o aprender a fazer selfies, aquilo que de mais potente os grupos de discussão com as jovens meninas

$$
\text { (C) ETD-Educação Temática Digital Campinas, SP v.20 } \quad \text { n.4 } \quad \text { p.1096-1116 out./dez. } 2018
$$


trouxeram, pois entendemos que a pedagoselfie permeia a produção das subjetividades contemporâneas. Na atualidade, é cada vez mais raro que alguém consiga não se deparar com uma versão de si feita em imagem. Além disso, sendo adeptos(as) ou não das fotografias, estamos todos(as) expostos(as) a muitas imagens ininterruptamente; dessa forma, de maneira intencional ou não, aprendemos lições sobre estética, sobre o valor e a manipulação das imagens. Aprendemos o que é considerado uma fotografia "bem feita" de paisagens, de viagens, de momentos do cotidiano, de animais, de pessoas, etc. Aprendemos também a avaliar quais selfies estão de acordo com as tendências atuais, que são "descoladas", "ousadas" e "bonitas". A pedagogia das selfies (pedagoselfie) é uma prática cultural do tempo presente, singularmente constituído pelo uso disseminado de aparatos tecnológicos de produção de imagens. Nesse sentido, a pedagogia das selfies é uma peça da complexa engrenagem dos modos de ver e ser visto(a), cujo funcionamento se infiltra cada vez mais cotidiana e intimamente, levando os indivíduos a transformarem seus corpos orgânicos em corpos-pixel passíveis de edição e apagamento. Percebemos, porém, que o sonho da perfeição digital se complica: o pesadelo dos corpos editados é, precisamente, o olhar permanente e incansável da alteridade.

\section{REFERÊNCIAS}

BRUNO, Fernanda. KANASHIRO, Marta. FIRMINO, Rodrigo. Introdução. In: BRUNO, F. KANASHIRO, M. FIRMINO, R. (Org.). Vigilância e visibilidade: espaço, tecnologia e identificação. Porto Alegre: Sulina, 2010. p. 7-13.

COSTA, Jurandir Freire. O vestígio e a aura - corpo e consumismo na moral do espetáculo. Rio de Janeiro: Garamond, 1998.

COSTA, Marisa Vorraber; SILVEIRA, Rosa Hessel; SOMMER, Luis Henrique. Estudos culturais, educação e pedagogia. Rev. Bras. Educ., Rio de Janeiro, n. 23, p. 36-61. 2003.

DINIZ, Debora. Pesquisa social e os Comitês de Ética no Brasil. In: FLEISCHER, S.; SCHUCH, P. (Org.). Ética e regulamentação na pesquisa antropológica. Brasília, DF: Letras Livres/Editora Universidade de Brasília, 2010. p. 183-192.

LIPOVETSKY, Gilles; SERROY, Jean. A estetização do mundo: viver na era do capitalismo artista. Tradução: Eduardo Brandão. São Paulo: Companhia das Letras, 2015.

MUELLER, Mary-Rose; INSTONE, Susan. Para além do consentimento informado: consentimento contínuo em pesquisa com seres humanos. Ciência \& Saúde Coletiva, n. 13, v. 2. p. 381-389, 2008.

ORTEGA, Francisco. Da ascese à bio-ascese ou do corpo submetido à submissão ao corpo. In: RAGO, Margareth; ORLANDI, Luiz B. Lacerda; VEIGA-NETO, Alfredo. Imagens de Foucault e Deleuze: ressonâncias nietzschianas. Rio de Janeiro: DP\&A, 2005, p.139-173

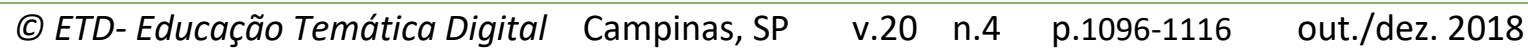


SÁ, Simone. P. POLIVANOV, Beatriz B. Presentificação, vínculo e delegação nos sites das redes sociais. Comunicação, mídia e consumo. São Paulo, ano 9, v. 9, n. 26, p. 13-36. 2012.

SANT'ANNA, Denise B. de. Corpos de passagem: ensaios sobre a subjetividade contemporânea. São Paulo: Estação Liberdade, 2001.

SANT'ANNA, Denise B. de. Transformações do corpo: controle de si e uso dos prazeres. In: RAGO, Margareth; ORLANDI, Luiz B. Lacerda; VEIGA-NETO, Alfredo (Org.). Imagens de Foucault e Deleuze: ressonâncias nietzschianas. Rio de Janeiro: DP\&A, 2005, p 99-110.

SIBILIA, Paula. A construção de si como um personagem real: autenticidade intimista e declínio da ficção na cultura contemporânea. Revista ECO-Pós. v. 15, n. 3, p. 22-46, Rio de Janeiro, 2012.

SIBILIA, Paula. O show do eu: a intimidade como espetáculo. Rio de Janeiro: Rio de Janeiro: Contraponto, 2016.

SIBILIA, Paula. O pavor da carne: riscos da pureza e do sacrifício no corpo-imagem contemporâneo. Revista FAMECOS, no 25, p. 68-84, set./dez., Porto Alegre, RS, 2004.

SOARES, Carmen L. A educação do corpo e o trabalho com as aparências: o predomínio do olhar. In: ALBUQUERQUE J. R.; VEIGA-NETO, A.; SOUZA FILHO, A. (Org.). Cartografias de Foucault. Belo Horizonte: Autêntica, 2009. p. 69-82

ZAGO, Luiz Felipe; GUIZZO, Bianca S.; SANTOS, Luis Henrique Sacchi dos. Problematizações éticas: perigos para a pesquisa em educação com gênero e sexualidade. Inter-ação. v. 41, n.2, p. 189-212, jan./abr., Goiânia, GO, 2016.

ZAGO, Luiz Felipe; SANTOS, Luis Henrique Sacchi dos. Os Retratos de Dorian G(r)ay - corpo, imagem e subjetividade. Comunicação, Mídia e Consumo, v. 11 n. 32, p. 93-117, set./dez., São Paulo, SP, 2014.

\footnotetext{
' Revisão gramatical do texto sob responsabilidae de: Lene Belon - E-mail: lenebelon@hotmail.com
} 